\title{
O professor que queremos
}

\author{
Gustavo Fitas Manaia'1,2, Jaqueline Victória Ciancaglini ${ }^{1}$, Lucy Miwa Sugawara ${ }^{1,2}$, Mariana de Sousa Prado Geraldo¹, \\ Thaiane Fagundes Vieira ${ }^{1}$ \\ ${ }^{1}$ Faculdade de Medicina do ABC (FMABC) - Santo André (SP), Brasil. \\ IInternational Federation of Medical Students Associations of Brazil (IFMSA Brazil) - São Paulo (SP), Brasil.
}

DOI: http://dx.doi.org/10.7322/abcshs.v40i3.788

Senhor Editor,

As escolas médicas buscam incessantemente mecanismos de avaliação dos seus docentes ${ }^{1}$. O tema é polêmico e, muitas vezes, tanto os docentes como os discentes se sentem insatisfeitos com os resultados ${ }^{2}$

Os docentes dos cursos de Medicina, frequentemente, médicos de formação, nem sempre possuem competências profissionalizadas para a prática de ensino e, ao longo de sua carreira, não recebem uma orientação pedagógica adequada ${ }^{3}$.

Além disso, o professor geralmente alia essa atividade à prática clínica e à pesquisa científica, dedicando-se parcialmente ao ensino.

Faltam estudos que busquem caracterizar a percepção dos docentes das escolas médicas quanto às suas aplicações práticas em sala de aula, ao seu preparo para o ensino e à importância que dá à carreira docente. Esse exercício de diálogo com os docentes poderia favorecer processos de autorreflexão crítica.

Estudantes da Faculdade de Medicina do ABC (FMABC) imbuídos deste propósito - desencadear processo reflexivo sobre a atividade docente - desenvolveram um questionário baseado no seu imaginário do que seria um "professor que queremos" (Anexo 1A)

Esse é um questionário semiestruturado que contém 2 perguntas abertas e 19 questões fechadas - sugerimos que seja utilizado o padrão de Escala Visual Analógica (EVA - Anexo 1B) para que os profissionais possam respondê-las de forma subjetiva, mas que possam ser quantificadas. Ainda mais, há em cada uma dessas
19 questões a oportunidade de o docente ampliar sua resposta quantitativa com perguntas em aberto.

A EVA tem sido utilizada na aferição da intensidade da dor no exame clínico, sendo sua escala composta por números inteiros de 0 a 10 , sendo 0 dor inexistente e 10 , dor máxima ${ }^{4}$.

$\mathrm{O}$ entrevistado marca um ponto na linha ou entre as extremidades, e o pesquisador mede a distância da extremidade inferior até o ponto respondido.

A reta horizontal aplicada neste trabalho tem $10 \mathrm{~cm}$ de comprimento, com suas metades delimitadas, e varia entre duas opções, que serão usadas de acordo com a questão a qual pertencem: "nada/nunca", ou "muito/sempre" ou "0\%/ 100\%" (Anexo 1A). A análise das respostas fornecidas pelos entrevistados poderá ser feita por meio da mensuração, com uma régua, do quão próximo de "nada/nunca", "muito/sempre" e "0\%/100\%" o docente assinalou na reta e poderá ser submetida a procedimentos de estatística descritiva (médias e desvios padrões).

As questões relacionadas à reta versam sobre o desempenho do professor em sala de aula, seu relacionamento profissional com os alunos e sua capacitação para a profissão docente.

Com esta carta, senhor Editor, queremos fornecer subsidios para avaliações docentes autorreflexivas que levem em conta aspectos valorizados pelos discentes.

Assim, esperamos que os resultados sejam menos controversos e sirvam para aprimorar os processos de ensino-aprendizagem nas escolas médicas.

\section{REFERÊNCIAS}

1. Rodrigues, SS. Políticas de Avaliação Docente: tendências e estratégias. Ensaio: aval pol públ educ. 2012; 20(77), 749-68

http://dx.doi.org/10.1590/S0104-40362012000400007

2. Al-Faris EA, Naeem N. Effective teaching in medical schools. Guiding principles. Saudi Med J. 2012;33(3): 237-43.
3. Stenfors-Hayes T, Hult H, Dahlgren LO. Three ways of understanding development as a teacher. Eur J Dent Educ. 2012;16(1):e151-7 http://dx.doi.org/10.1111/j.1600-0579.2011.00690.x.

4. Rubbo, AB. Escala Visual Analógica na avaliação da intensidade da dor pós-operatória de cirurgia bariátrica independente do uso de analgésicos. Tese (Doutorado) - Faculdade de Ciências Médicas da Santa Casa de São Paulo, São Paulo, 2010. 
Anexo 1: (A) Questionário proposto; (B) Escala Visual Analógica

\section{ITEM}

A 1.0 que é ser professor?

2. Como você decidiu ser professor?

3. Você considera seus métodos de avaliação dos alunos adequados?

a) Quais os métodos empregados? (Provas, trabalhos, seminários, etc.)

4. Planeja estímulos de aprendizagem?

a) Que estímulos?

5. Fornece aos estudantes material para estudo antes da aula?

a) De que forma? (e-mail, fotocópia...)

6. Quanto da sua aula está baseado em associação dos conceitos com a prática clínica?

a) Como você faz isso?

7. Com que frequência/quantidade/intensidade você estimula a participação, a curiosidade e o interesse dos alunos?

a) Como você faz isso?

8. A sua aula é descontraída e deixa os alunos confortáveis para se expressarem?

a) Quais recursos utiliza para isso?

9. Que ferramentas e oportunidades você propicia ao seu aluno para ele continuar o processo de aprendizagem?

10. Quanto da sua aula é ocupada com trabalho de grupo/equipe?

a) Como você seleciona esses grupos?

11. Com que frequência você procura saber dos alunos, como eles vão indo, ao longo do ano?

a) Como?

12. Você pergunta a eles como está indo o curso?

13. Que valores você imagina que transmite para os alunos como profissional?

14. O quanto você trabalha em sala de aula as diferenças de ritmo, estilo e velocidade de aprendizagem?

a) De que maneira percebe isso?

15. Você se atualiza sobre o conteúdo a ser ensinado?

a) Que meios utiliza?

16. Você se atualiza quanto à metodologia de ensino?

a) Que meios utiliza?

17. Quanto da sua semana é tomada pela profissão de professor?

18. Quanto da sua renda é acrescida pela profissão de professor?

19. Você já participou de algum curso para capacitação docente?
a) Qual?
b) Quando?
c) Por quanto tempo?

20. Quanto julga ser importante que os professores do curso de Medicina participem de capacitação docente?

21. Quanto você se sente preparado para a atividade docente?

Escala Visual Analógica (EVA) para intensidade das dores:

\section{RESPOSTA}

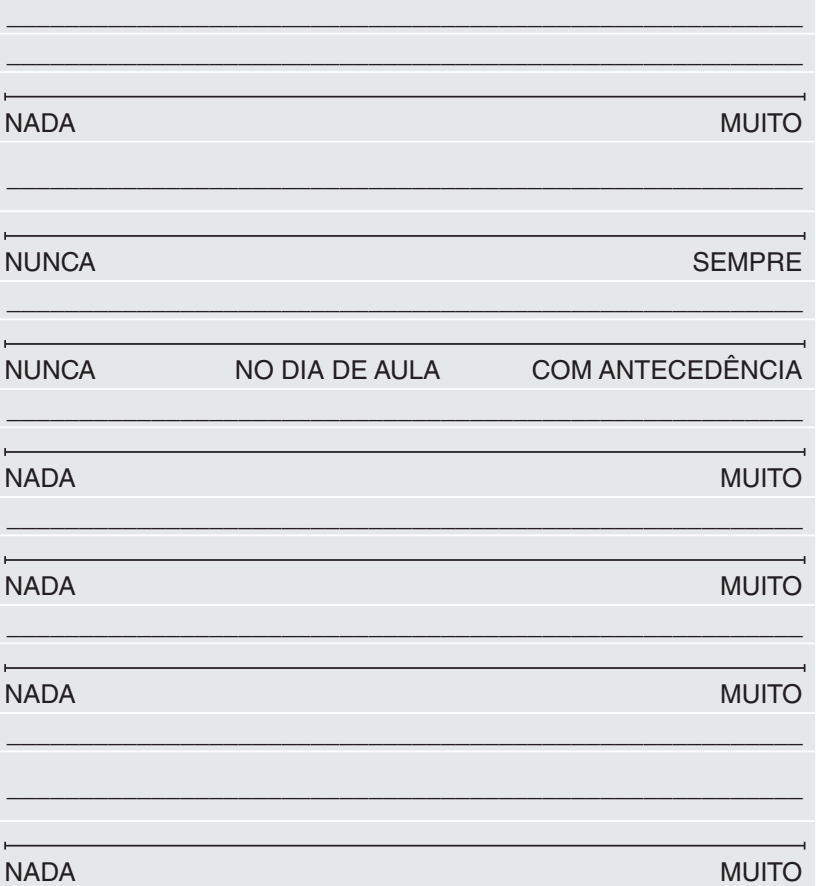

$\longdiv { \text { NUNCA SEMPRE } }$

\begin{tabular}{l}
\hline NUNCA SEMPRE \\
\hline
\end{tabular}

\begin{tabular}{ll}
\hline NADA MUITO \\
\hline
\end{tabular}

SEMPRE

$\overline{\text { NUNCA SEMPRE }}$

\begin{tabular}{lr}
\hline $0 \%$ & $100 \%$ \\
\hline $0 \%$ & $100 \%$ \\
\hline
\end{tabular}

\begin{tabular}{lr}
\hline \\
\hline \\
\hline NADA & MUITO \\
\hline NADA & MUITO
\end{tabular}

NADA

MUITO

\begin{tabular}{c|c|c|c|c|c|c|c|c|c|c|}
\hline 0 & 1 & 2 & 3 & 4 & 5 & 6 & 7 & 8 & 9 & 10 \\
\hline Nenhuma & Razoável \\
Pouca & Muita
\end{tabular}

(C) 2015 Manaia et al.

Este é um artigo de acesso aberto distribuído nos termos de licença Creative Commons 